\title{
Effects of Electromagnetic Field on Thyroid Functions in
}

\section{Rats}

Abdel Nasser Ismail Adam*, Abdel Rehman M. Taha*

\begin{abstract}
The effect of electromagnetic field (EMF) on serum thyroid stimulating hormone (TSH) and triiodothyronine-thyroxin (T3-T4) hormones levels of adult male Sprague-Dawley rats were studied. Fifty rats were used in three independent groups, 20 of which were control (without stress and EMF), 20 of which were exposed to $900 \mathrm{MHz}$ EMF and 10 of which were sham-exposed. The exposures were performed $30 \mathrm{~min} /$ day, for 5 days/week for 4 weeks to $900 \mathrm{MHz}$ EMF. Sham-exposed animals were kept under the same environmental conditions as the study groups except with no EMF exposure. The concentration of TSH and T3-T4 hormones in the rat serum was measured by using an enzyme liked immunsorbent assay (ELISA) method for TS, T3, and T4 hormones. TSH values and T3-T4 at the $900 \mathrm{MHz}$ EMF group were significantly lower than the sham-exposed group $(p<0.01)$. There were no statistically significant differences in serum TSH values and T3-T4 hormones concentrations between the control and the sham-exposed group $(p>0.05)$. These results indicate that $900 \mathrm{MHz}$ EMF emitted by cellular telephones decrease serum TSH and T3-T4 levels.
\end{abstract}

\section{INTRODUCTION}

The biological effect of electromagnetic field (EMF) emitted from mobile phones is a current debate and still a controversial issue. Therefore, little is known on the possible adverse effects on thyroid functions as mobile phone bio-effects are only a very recent concern. The aim of this study was to determine the biological effects of $900 \mathrm{MHz}$ radiofrequency (RF)
EMF on rat thyroid hormones(1). The erection of thousands of mobile telephone base-stations has raised concerns about possible health effects caused by an exposure to electromagnetic fields. Until now, no epidemiological study has addressed this issue.

Biological effects of electromagnetic field (EMF) and their consequences on human health are receiving increasing ${ }^{*}$ Physiology and Biophysics, Medical Research Institute, Alexandria University, Alexandria 
scientific interest and has become the subject of great public debate. The controversy has been stimulated by some epidemiologic studies that have reported a relation between magnetic field exposure and human diseases ${ }^{(2)}$.

If there is any impact of mobile telephones on health, it would affect almost everyone in the world(3). At the present, most of the mobile phones generally work at a frequency of $900 \mathrm{MHz}$ in the GSM systems. The cellular responses to various forms of radiation, including ionizing, UVradiation or exposure to electromagnetic fields are manifested as reversible or irreversible from structural to functional changes $^{(4-6)}$. Over the past two decades, there has been increasing interest in the biological effects and possible health outcomes of the weak, high frequency electric and magnetic fields ${ }^{(7)}$.

Some studies on the magnetic fields and cancer, reproduction, and neurobehavioral reactions have presented that different system diseases are related to the electromagnetic fields such as those similar to ones produced by mobile phones $^{(6-10)}$. Thyroid activity is regulated by the thyroid stimulating hormone (TSH) secreted by pituitary. Elevated TSH levels induce the thyroid to elaborate triiodothyronine (T3) and thyroxin (T4), a hormone which functions in at least 20 enzyme systems; one of its major influences involves the acceleration of protein synthesis.

Animal studies have shown that exposure to radiofrequency electromagnetic fields may alter the endocrine or the nervous systems and especially the thyrotropin secretion ${ }^{(11-16)}$. The aim of this study was to investigate whether the serum TSH and T3-T4 hormone levels of adult male SpragueDawley rats could be altered after exposure to the $900 \mathrm{MHz}$ GSM-like EMF generator. 


\section{MATERIAL AMD METHODS}

Fifty male Sprague-Dawley rats (12 weeks old, each weighing between 250 and $300 \mathrm{~g}$ at the start of experiment) were maintained under a 12-h light/12-h dark cycle in a temperature-regulated $(23 \pm 1 \circ \mathrm{C})$ animal room with a continuous free access to water and food. Animals were randomly grouped as follows: control group (without stress and EMF) ( $n=10)$, sham-exposed group $(n=20)$, and a $900 \mathrm{MHz}$ EMF $(n=$ 20), Fig.1 The $900 \mathrm{MHz}$ EMF group was exposed to $30-\mathrm{min} /$ day radiations for a period of 5 days/week. The EMF exposure period was at 10:00-11:00 a.m. in each day and lasted for 4 weeks. Sham-exposed group stayed in the experimental setup with the same conditions as the exposure groups without radiation exposure (exposure device off). Rats that were exposed to the $900 \mathrm{MHz}$ EMF were compared to control rats in respect to the serum TSH and T3-T4. At the end of 4 weeks, the rats were sacrificed and blood samples were collected through a cardiac puncture.

Blood samples were collected into the glass tubes without anticoagulant and were allowed to clot. It was centrifuged to obtain serum and stored at $-20 \circ \mathrm{C}$ until the assay. Serum TSH and total T3-total T4 hormone levels were measured using ELISA kit (Diagnostic Products Corporation, LA, USA). Statistical analysis: "SPSS 10.00 for Windows" was used for statistical evaluation in the study. Mann-Whitney $U$ test was performed to analyze the data. The results of serum TSH and T3-T4 hormone levels were given mean \pm S.D. The limit of statistical significance was $p<0.01$, two-side.

\section{RESULTS}

The effect of 900 EMF exposure on serum TSH and T3-T4 hormones levels of adult male Sprague-Dawley rats were studied in three independent experiments. Fig. 2 shows average serum TSH concentrations of the control, sham- 
exposed and 900MHz EMF groups.

A comparison of average serum TSH hormone with S.D. among control, shamexposed and $900 \mathrm{MHz}$ EMF groups. (*) Sham exposed vs. $900 \mathrm{MHz}$ EMF group $(p<0.01)$.The control group was marginally lower than those of the sham-exposed rats. However, there were no statistically significant differences in serum TSH concentrations between the control and the sham-exposed group $(p>0.05)$. On the contrary, the serum TSH concentrations of the rats exposed to the magnetic field were significantly lower than those of the shamexposed rats $(p<0.01)$.

The values were $0.26 \pm 0.05 \_I U ~ m l-1$ in

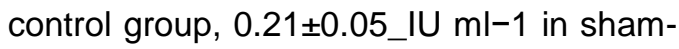
exposed group, and $0.15 \pm 0.04 \_\mathrm{IU} \mathrm{ml}-1$ in exposed group. The average serum T3-T4 hormones concentrations of the control, sham-exposed and 900MHz EMF groups are presented in Figs. 3 and 4. From these figures, it can be seen that the T3-T4 hormones concentrations in the rats exposed to the EMF has significantly lower than in those sham-exposed rats $(p<0.01)$. Nevertheless, the serum T3-T4 hormones concentrations of the control group were marginally higher than those of the shamexposed rats.

However, there were no statistically significant differences in serum T3-T4 hormones concentrations between the control and the sham-exposed group $(p>$ 0.05). The values were T3 $=127.45 \pm 11.04$ ng dl-1, T4 $=6.23 \pm 0.54 \mathrm{~g} \mathrm{dl}-1$ in the control group; T3 = 117.66 \pm 10.71 ng dl-1, $\mathrm{T} 4=5.98 \pm 0.66 \mathrm{~g} \mathrm{dl}-1$ in the shamexposed group and T3 $=92.67 \pm 9.79 \mathrm{ng}$ $\mathrm{dl}-1, \mathrm{~T} 4=5.9 \pm 0.53 \mathrm{~g} \mathrm{dl}-1$ in the exposed group, respectively.

\section{DISCUSSION}

Frequency is the rate at which electromagnetic fields change direction, and is measured in hertz $(\mathrm{Hz})$. One mega hertz is 1 million cycles/s. Analogue telephones use frequencies between 800 and $900 \mathrm{MHz}$; digital telephones use 
frequencies between 1800 and $1990 \mathrm{MHz}$;

while micro wave ovens use frequency of 2450 MHz. Today's mobile telephones, with a total power output of $2 \mathrm{~W}$, are estimated to produce insignificant local heating, which is unlikely to produce any deleterious effects.

An accumulated body of evidence published over the last three decades has identified, investigated and quantified the responses of mammalian neuroendocrine and intercellular hormonal control systems to radiofrequency (RF)-EMF exposure.

In particular, the mechanisms for the production and control for corticosteroid, thyroid and growth hormones have been extensively investigated(11,17-19). Hormones acting on reproductive tissues, including $\mathrm{LH}, \mathrm{FSH}$, and prolactin, have received less attention. Characterization of established effects show that they result from tissue heating, and are generally similar to nonspecific stress responses ${ }^{(20,11)}$.

It is known that the effect and the amount of damage caused by radiation is positively correlated with the exposure time ${ }^{(21)}$. We studied the effect of $900 \mathrm{MHz}$ GSM-like frequency EMF on serum TSH, T3, and T4 hormones levels of rats. According to our results, measured serum TSH and T3, T4 values at the $900 \mathrm{MHz}$ EMF group were significantly lower than the sham-exposed group. Thyroid stimulating hormone acts on the thyroid gland and stimulates secretion of thyroid hormones. It was reported increase thyroxine and triiodothyronine secretion when the thyroids of dogs were exposed to varying levels of $2.45 \mathrm{GHz}$ RFEMF at estimated SARs of $58-190 \mathrm{~W} / \mathrm{kg}$ for $2 \mathrm{~h}$. A follow up study found decreased circulating thyroxine ${ }^{(19)}$ and TSH levels in rats when a rectal temperature rise to $40{ }^{\circ} \mathrm{C}$ had been caused by whole body exposure to 2.45 $\mathrm{GHz}$ RFEMF at $4 \mathrm{~W} / \mathrm{kg}^{(22)}$. The research previously referenced Lotz and Podgorski(23) using rhesus monkeys, which found an increase in serum cortisol levels 
with increased rectal temperature when exposed to $1.29 \mathrm{GHz}$ RFEMF at 3-4 W/kg, did not report a change in serum growth hormone levels or thyroxin.

De seze et al.,(24) showed that TSH was a $21 \%$ decrease in male volunteers chronically exposed to GSM cell phone fields $2 \mathrm{~h} /$ day, 5 days/week for 1 month.

Our TSH results in rats exposed to the $900 \mathrm{MHz}$ EMF magnetic field are in agreement with data reported by De seze et al. Levels of T3 and T4 in rats exposed the $900 \mathrm{MHz}$ EMF are in agreement with data reported by Zagorskaya and Rodina $(1990)^{(25)}$. These authors found lowered concentration of thyroid hormones during 2 months after a single exposure of rats to 20 mT extremely low frequency (ELF)-EMF. Selmaoui et al.(2) reported insignificant differences in serum T3 and T4 levels between sham-exposed men and men exposed to continuous and intermittent 50 $\mathrm{Hz}$ magnetic field of $10 \mathrm{~T}$ for one night. Also, one of the early studies of ELF-EMF influence on thyroid gland provided by Lafreniere and Persinger (1979)(26) had shown that no alterations in serum T3 and T4 concentrations or in the number of thyroid follicles, were found in rats exposed to $0.5 \mathrm{~Hz}$ EMF perinataly and/or as adults.

On the contrary, Udintsev et al., $(1978)^{(27)}$ found increased levels of circulating $\mathrm{T} 4$ and $\mathrm{TSH}$ in rats exposed to $50 \mathrm{~Hz}$ EMF of $20 \mathrm{mT}$ for $18 \mathrm{~h}$, but a decreased concentration of circulating thyroid hormones after a single exposure to EMF.

Whole body averaged SAR measurements are of importance to predict elevation of the core body temperature. Experimental studies suggest that core body temperature rises significantly at whole body average SAR above 1-4 $\mathrm{W} / \mathrm{kg}^{(28-30)}$. The current study has shown a lowering effect to TSH and thyroid hormones. EMF exposure may influence the negatively the iodine uptake in the thyroid gland, and may influence with 
increased temperature effect on pituitary gland. According to this study, frequency of $900 \mathrm{MHz}$ EMF produced by digital mobile radio-telephones decreases $\mathrm{TSH}$ and that the degree of $\mathrm{TSH}$ and thyroid thyroid hormones under the conditions hormones suppression by EMF of highused. However, further investigations (for frequency.

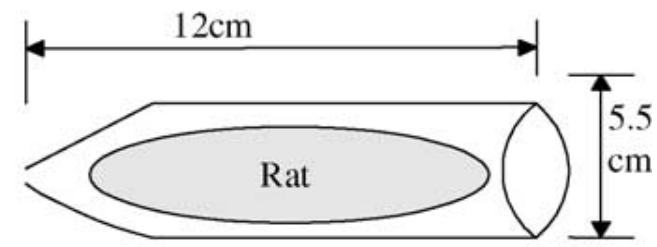

$900 \mathrm{MHz}$

EMF Generator example, if a larger number of animals are studied or if the duration of exposure was longer) are needed in order to clearly show

Fig.1. Schema of EMF exposure device 


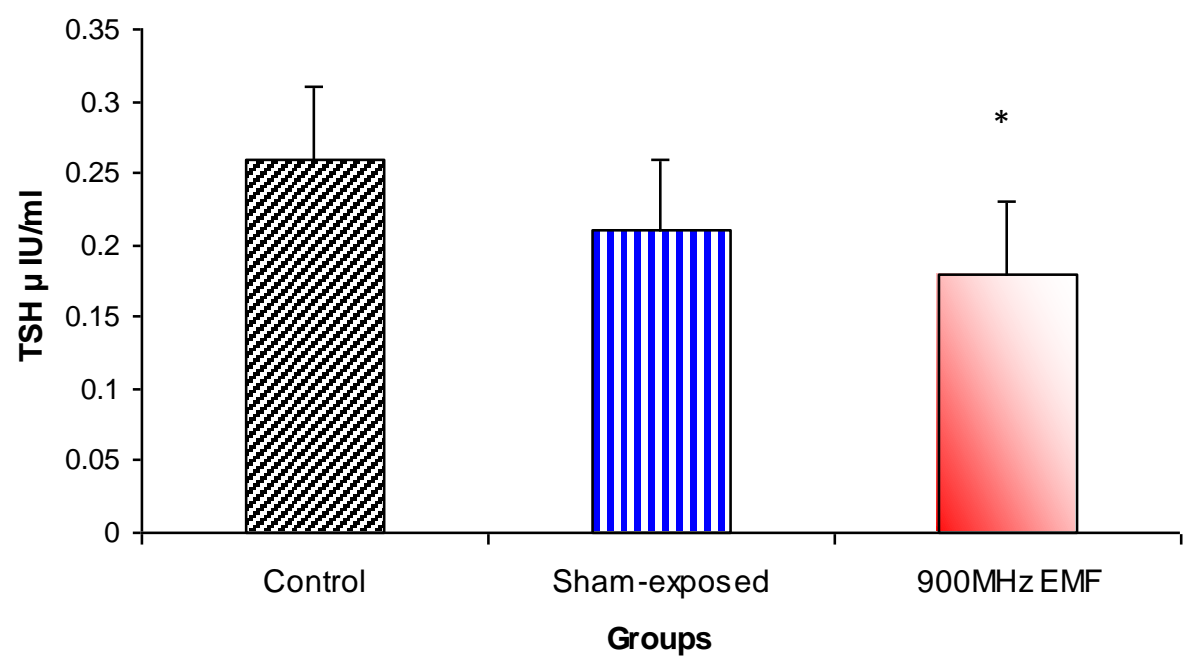

Fig. 2. A comparison 'of average serum TSH hormone among control, shamexposed and $900 \mathrm{MHz}$ EMF groups. (*) Shamexposed vs. $900 \mathrm{MHz}$ EMF group $(p<0.01)$

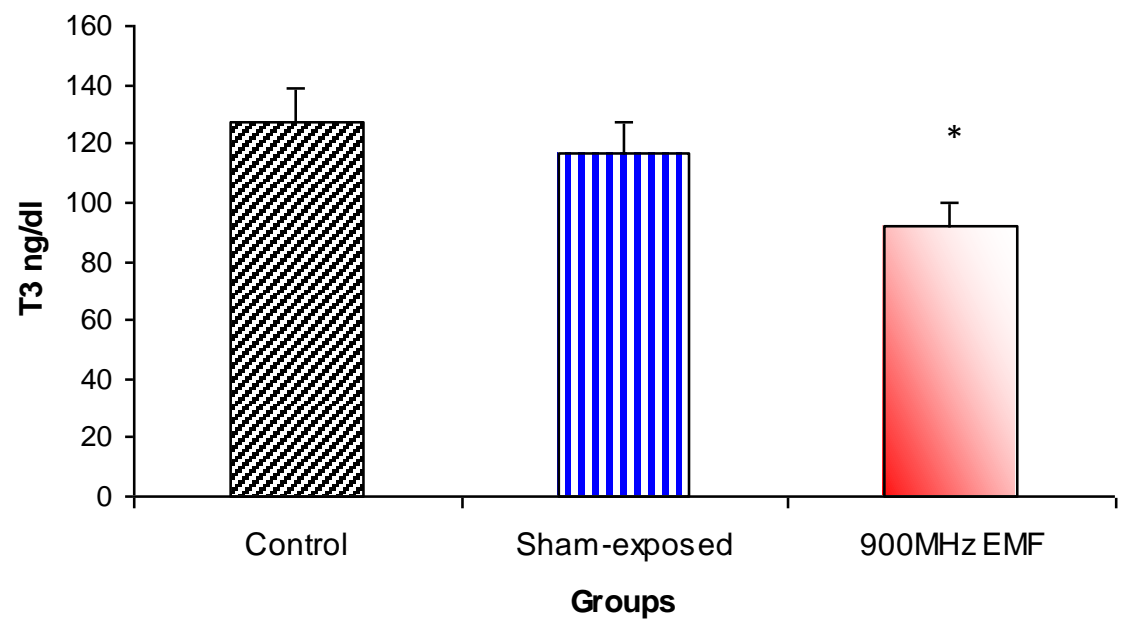

Fig. 3. A comparison of average serum T3 hormone among control, sham-exposed and $900 \mathrm{MHz}$ EMF groups. ( $\left.{ }^{*}\right)$ Sham-exposed vs. $900 \mathrm{MHz}$ EMF group $(p<0.01)$ 


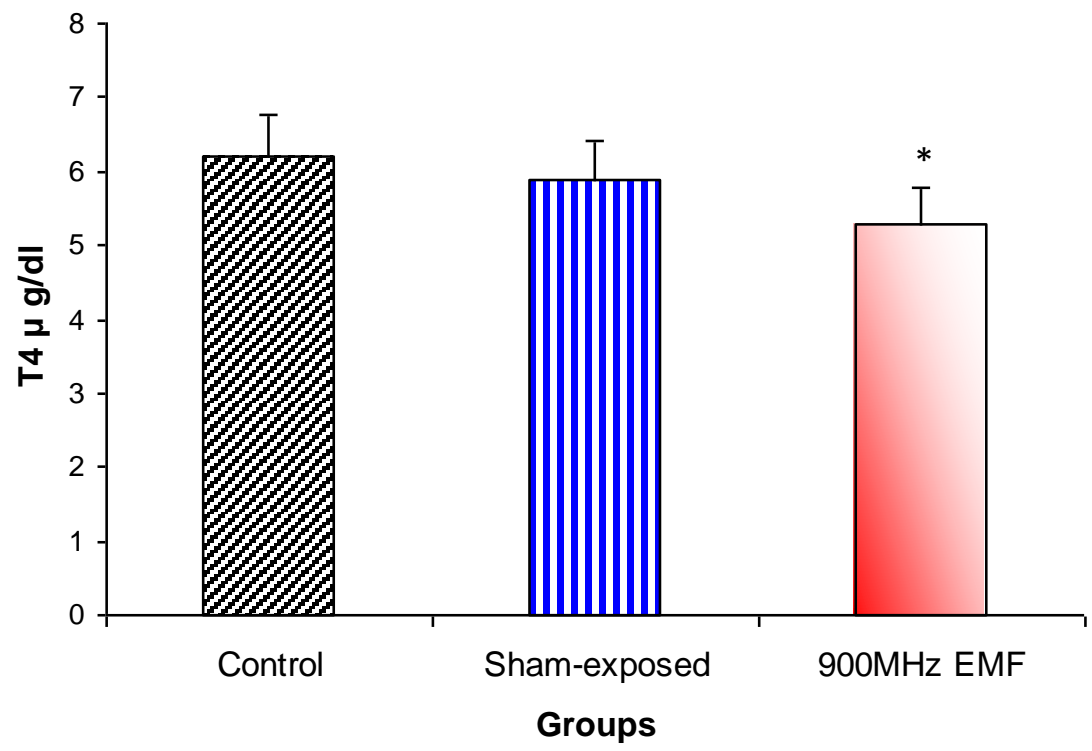

Fig. 4. A comparison of average serum T4 hormone among control, sham-exposed and $900 \mathrm{MHz}$ EMF groups. ( $\left.{ }^{*}\right)$ Sham-exposed vs. $900 \mathrm{MHz}$ EMF group $(p<0.01)$

\section{REFERENCES}

1. Vesna Rajkovic, Milica Matavulj, Olle Johansson. Light and electron microscopic study of the thyroid gland in rats exposed to power-frequency electromagnetic fields. The Journal of Experimental Biology 2007;209:33223328

2. Selmaoui B, Lambrozo J, Touitou Y. Endocrine functions in young men exposed for one night to a $50-\mathrm{Hz}$ magnetic field. A circadian study of pituitary, thyroid and adrenocortical hormones. Life Sci. 1997;61(5): 473486.

3. Repacholi $\mathrm{MH}$. Health risks from the use of mobile phones. Toxicol. Lett.

2001;120:323-31.

4. Rothman KJ, Loughlin JE, Funch DP, Dreyer NA. Overall mortality of cellular telephone customers. Epidemiology. 1996;7, 303-305.

5. Somosy Z. Radiation response of cell organelles. Micron. 2000;31, 165-181.

6. Cox DR. Communication of risk: health hazards from mobile phones. J. R. Stat. Soc. Ser. A (Stat. Soc.) 2003;166:241-245.

7. Knave B. Electromagnetic fields and health outcomes. Ann. Acad. Med. Singapore. 2001;30:489-93.

8. Leszczynski D, Joenvaara S, Reivinen J, Kuokka R. Nonthermal activation of 
the sp27/p38MAPK stress pathway by mobile phone radiation in human endothelial cells: molecular mechanism for cancer- and bloodbrain barrier-related effects. Differentiation. 2002;70:120-129.

9. Bartsch $H$, Bartsch $C$, Seebald E, Deerberg F, Dietz K, Vollrath L, et al. Chronic exposure to a GSM-like signal (mobile phone) does not stimulate the development of DMBAinduced mammary tumors in rats: results of three consecutive studies. Radiat. Res. 2002;157:183-90.

10. Bortkiewicz A. A study on the biological effects of exposure mobilephone frequency EMF. Med. Pr. 2001;52:101-6.

11. Lu ST Lebda N, Pettit S, Michaelson SM. Microwave induced temperature, corticosterone, and thyrotropin interrelationships. J Appl Physiol. 1981;50:399-405

12. Lu ST, Lebda NA, Lu SJ, Pettit S, Michaelson SM. Effects of microwaves on three different strains of rats. Radiat. Res. 1987;110:173-91.

13. Michaelson SM. Biological Effects and Dosimetry of Non- Ionising Radiation: Radiofrequency and Microwaves Energies NATOAdvanced Study Institutes Series: Series A, Life Sciences, vol. 49, New York. 1983.

14. Lai H, Horita A, Chou CK, Guy AW. Effects of lowlevel microwave irradiation on hippocampal and frontal cortical choline uptake are classically conditionable. Pharmacol. Biochem. Behav. 1987;27:635-9.

15. Lai H, Carino MA, Horita A, Guy AW. Low-level microwave irradiation and central cholinergic systems. Pharmacol. Biochem. Behav. 1989;33, 131-8.

16. Lai $H$. Research on the neurological effects of non-ionizin gradiation at the
University of Washington. Bioelectromagnetics. 992;13:513-526.

17. LotzWG, Michaelson SM. Temperature and corticosterone relationships in microwave-exposed rats. J. Appl. Physiol. 1978;44:438-45.

18. magin RL, LU S, Michaelson SM. Stimulation of dog thyroid by local application of high intensity microwaves. Am. J. Physiol. 1977;233:E363-E368.

19. Michaelson SM, Houk WM, Lebda NJ, Lu ST, Magin RL. Biochemical and neuroendocrine aspects of exposure to microwaves. Ann. N. Y. Acad. Sci. 1975;247:21-45.

20. Roberts NJ, Michaelson SM, Lu ST. The biological effects of radiofrequency radiation. Int. J. Radiat. Biol. 1986;50:379-420.

21. MoustafaYM, Moustafa RM, Belacy A, Abou-El-Ela SH, AliFM. Effects of acute exposure to the radiofrequency fields of mobile phones on plasma lipid peroxidase and antioxidase activities in human erythrocytes. J. Pharmaceut. Biomed. Anal. $2001 ; 26: 605-8$.

22. Lu ST, Lebda N, Pettit S, Michaelson SM. Delineating acute neuroendocrine responses in microwave-exposed rats. J. Appl. Physiol. 1980;48, 927-32.

23. Lotz WG, Podgorski RP. Temperature and adrenocortical responses in rhesus monkeys exposed to microwaves. J. Appl. Physiol. 1982;53: 1565-71.

24. De seze R, Peray PF, Miro L. Gsm radiocellular telephones do not disturb the secretion of antepituitary hormones in humans. Bioelectromagnetics. 1998;19:271-8.

25. Zagorskaya EA, Rodina GP. Responses of the endocrine system and peripheral blood of rats to single and chronic effects of a pulsed low frequency electromagnetic field. 
Kosm. Biol. Aviokosm. Med. 1990;24 (2):56-60.

26. Lafreniere GF, Persinger MA. Thyroid morphology and activity does not respond to ELF electromagnetic field exposures. Experientia. 1979;35(4):561-2.

27. Udintsev NA, Serebrov VY, Tsyrov GI. Vliyanie peremennogo magnetnogo polya promyshlenoj chastoty na funktsionalnoe sostoyanie shchitovidnoj zhelezi i pogloshehenie tiroksina organamikrys. Bull Eksper Biologii i Meditsini. 1978;86:544-546.

28. Elder JA, Cahill DF. Biological Effects
Of

Radiofrequency

Radiation.USEnvironmental protection Agency, EPA-600/8-83-026. 1984.

29. Goldon CJ, Long MD, Fehiner KS, Stead AG. Body temperatures in mouses, hamster, and rat exposed to radiofrequency radiation: an interspecies comparison. J. Therm. Biol. 1986;11:59-65.

30. IEEE. IEEE Standard for Safety Levels with Respect to Human Exposure to Radiofrequency Electromagnetic Field, $3 \mathrm{kHz}$ to 300 $\mathrm{GHz}$, vol. C95. New York Institute of Electrical and Electronic Engineers, pp. 1-1991. 1992. 